\title{
A Validated Stable HPLC Method for the Simultaneous Determination of Rifampicin and 25-O-Desacetyl Rifampicin - Evaluation of in vitro Metabolism
}

\author{
Saneesh Kumar ${ }^{1 *}$, Patrick J. Bouic ${ }^{2,3}$ and Bernd Rosenkranz ${ }^{1}$ \\ ${ }^{1}$ Division of Clinical Pharmacology, Department of Medicine, University of Stellenbosch, Tygerberg, Cape Town, South Africa \\ ${ }^{2}$ Division of Medical Microbiology, Faculty of Health Sciences, University of Stellenbosch, Cape Town, RSA \\ ${ }^{3}$ Synexa Life Sciences, Montague Gardens, Cape Town, RSA
}

Received: 27 July 2017; accepted: 10 December 2017

\begin{abstract}
A simple, efficient, and stable high-performance liquid chromatography (HPLC) separation method for a combination of rifampicin (RIF), its major metabolite 25-O-desacetyl rifampicin (25ODESRIF), and neostigmine (NEO) was developed and validated. The drugs individually, and in combination, were analyzed using a Waters Alliance 2695 HPLC coupled with 2996 photodiode array detector (PDA). Successful separation of combined drugs was achieved by gradient elution on a reverse-phase C-18 Phenomenex Luna column, using a mobile phase consisting of water and methanol at detection wavelength of $254 \mathrm{~nm}$. The HPLC retention times were consistent at $\pm 7.70 \mathrm{~min}, \pm 8.25 \mathrm{~min}$, and $\pm 10.70 \mathrm{~min}$ for RIF, 25ODESRIF, and NEO, respectively. The regression data for the calibration plots exhibited linear relationship $\left(R^{2}=0.995\right)$ in the range of $0-200 \mu \mathrm{M}$ for both RIF and 25ODESRIF, and the lower limit of detection (LLOD) and lower limit of quantification (LLOQ) were calculated at $5.86 \mu \mathrm{M}$ and $17.75 \mu \mathrm{M}$ for RIF and $7.78 \mu \mathrm{M}$ and $23.57 \mu \mathrm{M}$ for 25ODESRIF, respectively. The method was evaluated using in vitro human liver microsomes (HLMs) assays, and linearity was established for the $15,30,45$, and $60 \mathrm{~min}$ incubations $\left(R^{2}=0.99\right)$. The formation of 25ODESRIF was characterized by hyperbolic kinetics $\left(K_{\mathrm{m}} 48.23 \mu \mathrm{M}, V_{\max } 1.233 \mathrm{pmol} / \mathrm{min} / \mathrm{mg}\right.$ protein, and $\mathrm{CL}_{\text {int }} 0.026 \mu \mathrm{l} / \mathrm{min} / \mathrm{mg}$ protein). The method was applied in HLM assays to understand the herb-drug interaction (HDI) potential of Althaea officinalis, a popular African herb consumed by tuberculosis (TB) patients, with RIF. None of the extracts of $A$. officinalis inhibited the esterase-mediated metabolism pathway of RIF, compared to the positive control nelfinavir $\left(\mathrm{IC}_{50}=9.59 \mu \mathrm{M}\right)$. The method provides a tool for quantifying RIF and 25ODESRIF in in vitro drug metabolism assays as well as investigating herb- and drug-drug interactions (DDIs).
\end{abstract}

Keywords: HPLC, C-18, rifampicin, 25-O-desacetyl rifampicin, neostigmine, human liver microsomes, MichaelisMenten kinetics, Althaea officinalis, herb-drug interaction

\section{Introduction}

Rifampicin (RIF) (3-[4-methyl piperazinyl-iminomethyl] rifamycin SV; rifampin) is a first-line antibiotic along with isoniazid (INH), pyrazinamide (PYR), ethambutol (ETB), and streptomycin (STP) in the treatment of pulmonary and extrapulmonary tuberculosis (TB) and has a unique role in the killing of semi-dormant tubercle bacilli (Mycobacterium tuberculosis) [1].

The World Health Organization recommends a 6-month regimen comprising RIF, INH, PYR, and ETB which are given together for the first 2 months followed by RIF and INH therapy for the next 4 months. RIF is mainly eliminated in the bile and then reabsorbed; hence, enterohepatic circulation ensues. The drug is deacylated into its microbiologically active metabolite 25-O-desacetyl rifampicin (25ODESRIF), by esterases or by enzymes present in microsomal cells [2]. 25ODESRIF is less absorbable as compared to the parent drug [3].

RIF is used as an inducer of cytochrome P450 3A4 (CYP 3A4) to analyze the effect of herbal medicine on the activity of this enzyme $[4,5]$. It induces gut and liver (hepatic) CYP3A4 and autoinduces its own metabolism [6]. P-glycoprotein (P-gp), along with B-esterases, is involved in disposition of rifampicin [7].

Very few high-performance liquid chromatography (HPLC) methods have been developed for the quantification of RIF and its metabolite 25ODESRIF, in plasma [8-10] and urine

* Author for correspondence: saneesh.7.kumar@gmail.com
[11-14]. These HPLC methods involve various procedures which can be time-consuming. This is of critical importance especially in assays involving HLMs and other liver fractions (S9, hepatocytes), to identify the metabolites and also quantify the rate of drug metabolism, as well as for major pharmacokinetic studies as well as herb-drug interaction (HDI) and drugdrug interaction (DDI) studies. Metabolites may interfere with the assay when analyzing parent drugs [15]. Rifampicin induces the metabolism of many drugs, including antiretroviral drugs (ARVs) such as nevirapine metabolized by the CYPs, predominantly CYP3A4 and CYP2B6 [16, 17]. Few in vitro studies have assessed $K_{\mathrm{m}}$ and $V_{\max }$ kinetic parameters of rifampicin in human liver microsomes.

RIF-induced CYP3A4 activation and expression models have been used for predicting the pharmacokinetics of CYP3A4 substrate drugs as well as clinically relevant DDI [18]. Most of the in vitro HDI studies have investigated the role of RIF as an inducer of CYP3A4 along with other drugs and herbal extracts; less information is available on the effect of herbal medicines on the esterase-mediated metabolism pathway of RIF to 25ODESRIF. Assessment of the metabolic disposition of RIF and of possible inhibitory/inducing effects of herbal medicines would be very important.

Althaea officinalis L. (Malvaceae), commonly called "marshmallow" (Baer-ul-Khtmk [African/Arabic]; Gulkhairo [Pers.]), is a perennial species indigenous to Africa, which is used as an ornamental plant and a medicinal plant by TB patients [19-21].

This is an open-access article distributed under the terms of the Creative Commons Attribution-NonCommercial 4.0 International License (https://creativecommons.org/licenses/by-nc/4.0/), which permits unrestricted use, distribution, and reproduction in any medium for non-commercial purposes, provided the original author and source are credited, a link to the CC License is provided, and changes - if any - are indicated. 
The present research describes an HPLC-PDA method for the detection, separation, and quantitation of RIF and its principle metabolite 25ODESRIF, which is robust with a shorter analysis time and selective in the presence of first-line anti-TB drugs as well as their metabolites. This study is also unique in the perspective of determining the kinetics of rifampicin $\left(K_{\mathrm{m}}\right.$ and $\left.V_{\max }\right)$ based on the metabolite formation using HLM assays and is applied in investigating the HDI of RIF with the herbal extracts of A. officinalis, by measuring the enzyme kinetics of 25ODESRIF.

\section{Experimental}

Materials and Reagents. Pure 25ODESRIF and NEO were obtained from Clearsynth Labs Ltd. (Mumbai, India) while RIF and nelfinavir mesylate hydrate (NELF) were obtained from Sigma-Aldrich (Steinheim, Germany). HPLC-grade acetonitrile, methanol, and ethanol were purchased from Sigma-Aldrich (Steinheim, Germany) and ethyl acetate from BDH Chemicals (England). High purity water was prepared by passage through a Millipore system (Millipore, Billerica, MA, USA) and was used as the mobile phase. The HLM screening was performed using pooled human liver microsomes (mixed gender) from Xenotech LLC, USA along with glucose-6-phosphate sodium salt, glucose6-phosphate dehydrogenase, magnesium chloride, phosphate buffer solution of $1 \mathrm{M}$, and $\beta$-nicotinamide adenine dinucleotide phosphate hydrate (NADPH) from Sigma-Aldrich (Steinheim, Germany).

Preparation of Standards. The stock solutions for RIF, 25ODESRIF, and NEO were prepared at $4 \mathrm{mM}$ concentrations, in methanol, and the dilutions were made from the same with diluents: a mixture of water and methanol in the ratio $50: 50 \mathrm{v} / \mathrm{v}$ spiked with the internal standard NEO $(20 \mu \mathrm{M})[22,23]$ for the HPLC analysis. Dilutions were calculated from the stock solution of RIF for all the pharmacokinetic assays. All solutions were freshly prepared and filtered using $0.22 \mu$ syringe filters, before being subjected to HPLC analysis.

Plant Material and Extraction. The dried roots of $A$. officinalis (Malvaceae) were obtained in packed form, from Pharma Germania, Benoni, Gauteng (certificate of analysis no. 471255).

Four grams of the powdered roots were exhaustively extracted with purified water after boiling and also with HPLC grade methanol, ethanol, and ethyl acetate (made up to $500 \mathrm{~mL}$ for 9 days). The extract solutions were separately filtered and evaporated at $50{ }^{\circ} \mathrm{C}$ using a concentrator-freeze drier (miVac, England) to complete dryness to produce the aqueous (yield: $\pm 1166.54 \mathrm{mg}, 29.16 \% \mathrm{w} / \mathrm{w}$ ), methanol (yield: $\pm 731.43 \mathrm{mg}, 18.29 \% \mathrm{w} / \mathrm{w}$ ), ethanol (yield: $\pm 426.2,10.66 \% \mathrm{w} / \mathrm{w}$ ), and ethyl acetate extracts (yield: $\pm 574.93 \mathrm{mg}, 14.37 \% \mathrm{w} / \mathrm{w}$ ) of A. officinalis.

HPLC Instrumentation and Chromatographic Conditions. The Waters Alliance 2695 Separations Module with 2996 PDA Diode Array Detector HPLC System was used for method development and validation. The output signal $(254 \mathrm{~nm})$ was monitored and processed using QuickStart Empower Waters 2002 software. A Phenomenex Luna C-18 $(150 \times 4.6 \mathrm{~mm}, 5 \mu)$ column was used for the HPLC studies and method development, as well as the pharmacological evaluation and the HDI analysis, at column oven temperature of $27^{\circ} \mathrm{C}$.

Detection and Separation Method. Satisfactory separations were achieved on the C-18 Phenomenex Luna column $(150 \times$ $4.6 \mathrm{~mm}, 5 \mu)$, by gradient elution using mobile phase comprising of water (A)-methanol (B) at a flow of $0.8 \mathrm{~mL} / \mathrm{min}$. The gradient solvent program was set as $T$ T min/\%solution B at $0 / 10,5 / 80,10 / 95,9 / 80,11.5 / 10$, and 12.5/10. The detection wavelength was maintained at $254 \mathrm{~nm}$ (Table 1). All mobile phases were filtered using $0.22 \mu$ membrane solvent filters (Merck Millipore, USA). The column oven temperature was maintained at $27{ }^{\circ} \mathrm{C}$, and the injection volume was $15 \mu \mathrm{L}$. A post runtime of 2 min was maintained between each injection.

Method Validation. The method was validated for accuracy, linearity, and precision. LLOD and LLOQ were determined based on signal-to-noise ratio of 3 and 10, respectively, as per International Conference on Harmonization (ICH) guidelines [24]. The signal-to-noise ratio was determined by comparing measured signals from samples with known lowest concentrations of the analyte with those of blank samples following two replicate injections and establishing the minimum concentration at which the analyte can be reliably detected or quantified.

In Vitro Evaluation of Rifampicin Kinetics. The method was validated using HLM assay, by incubating RIF as the substrate. Briefly, a standard $200 \mu \mathrm{L}$ incubation mixture containing liver microsomes $(0.25 \mathrm{mg} / \mathrm{mL}$ protein concentration), RIF $(100 \mu \mathrm{M})$ in $0.2 \mathrm{M}$ phosphate buffer, $\mathrm{pH} 7.4$, at $37^{\circ} \mathrm{C}$ was incubated for $15,30,45$, and $60 \mathrm{~min}$, in duplicates. The reactions were initiated with NADPH (final concentration $1.3 \mathrm{mM}$ ) along with the cofactors magnesium chloride (final concentration $3.3 \mathrm{mM}$ ), glucose-6-phosphate (final concentration $1.3 \mathrm{mM})$, and glucose-6-phosphate dehydrogenase $(1 \mathrm{U} / \mathrm{mL})$ and then terminated with $200 \mu \mathrm{L}$ of chilled acetonitrile spiked with the internal standard NEO $(20 \mu \mathrm{M})$. The samples were centrifuged using $0.22 \mu$ polypropylene centrifuge tube filters

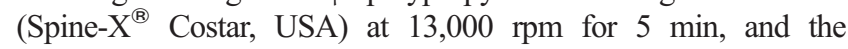
supernatants were subjected to HPLC analysis.

For determining the kinetics of RIF, various concentrations in the range of $0-150 \mu \mathrm{M}$ were incubated with HLM for

Table 1. The HPLC-PDA parameters for separation method

\begin{tabular}{l} 
Reference standard drug \\
\hline Structure
\end{tabular}


30 min using the same procedure as above; the reactions were terminated using $200 \mu \mathrm{L}$ of chilled acetonitrile spiked with the internal standard and centrifuged, and the top layer of the supernatant was subjected to HPLC analysis. The optimal incubation time (30 $\mathrm{min})$ and the concentration of HLM $(0.25 \mathrm{mg} / \mathrm{mL}$ protein) for the kinetics study was selected based on the rate of metabolite formation from the time-variant incubations (Figure $3 b$ ). Apparent kinetic constants $\left(K_{\mathrm{m}}\right.$ and $\left.V_{\mathrm{max}}\right)$ were estimated by fitting formation rates of metabolite versus substrate concentrations to the appropriate kinetic equations by nonlinear regression analysis using GraphPad Software Inc. (San Diego, CA; www.graphpad.com) Prism version 5.00 for Windows.

In Vitro Inhibition Screening Assays - HLM, Herbal Extract, and Rifampicin. The method was applied for analyzing herb-drug interactions of RIF with A. officinalis. The inhibitory potential of the extracts (aqueous, methanol, ethanol, and ethyl acetate) of $A$. officinalis was assessed using a twopoint screening with HLM, maintaining the final concentrations of each extract at 20 and $200 \mu \mathrm{g} / \mathrm{mL}$. Based on the kinetic constant $\left(K_{\mathrm{m}}\right)$ determined and the optimal incubation conditions, $48 \mu \mathrm{M}$ RIF was used as substrate to determine the formation of 25ODESRIF, with $20 \mu \mathrm{M}$ NEO as the internal standard. Briefly, a standard $200 \mu \mathrm{L}$ incubation mixture containing HLM and substrate $(0.25 \mathrm{mg} / \mathrm{mL}$ protein concentration for $48 \mu \mathrm{M}$ RIF) in $0.2 \mathrm{M}$ phosphate buffer (pH 7.4) and the plant extract (final concentration of 20 and $200 \mu \mathrm{g} / \mathrm{mL}$, dissolved in $<1 \%$ solvent) at $37{ }^{\circ} \mathrm{C}$ was incubated for $30 \mathrm{~min}$, in duplicates; the reactions were initiated using the

same cofactor mix composition as described earlier. The reactions were terminated using $200 \mu \mathrm{L}$ of chilled acetonitrile spiked with the internal standard and centrifuged, and the top layer of the supernatant was analyzed using HPLC. NELF (10 and $75 \mu \mathrm{M}$ ) was used as inhibitor control for the RIF metabolic pathway, based on the assumption that certain CYP inhibitors could also inhibit esterases [25].

The amount of 25ODESRIF formed relative to the control was expressed in percentage remaining activity and calculated as in equation below:

$\%$ residual activity $=($ test - test control $)$

$$
/(\text { control }- \text { control blank }) \times 100 \%
$$

Statistical analysis of the half inhibitory concentration $\left(\mathrm{IC}_{50}\right)$ was done based on to the two-point screening. The percentile of residual activity was plotted against the log-transformed concentrations (of the herbal extract or the positive control). Non-linear

Table 2. Regression statistics of RIF and 25ODESRIF

\begin{tabular}{lcc}
\hline Parameters & RIF & 25ODESRIF \\
\hline Linearity range $(\mu \mathrm{M})$ & $0-200$ & $0-200$ \\
Correlation coefficient & 0.9932 & 0.9976 \\
Standard error & 1.6181 & 2.1669 \\
Intercept coefficient & 16.9659 & 18.8773 \\
LLOD $(\mu \mathrm{M})$ & 5.86 & 7.78 \\
LLOQ $(\mu \mathrm{M})$ & 17.75 & 23.57 \\
\hline
\end{tabular}

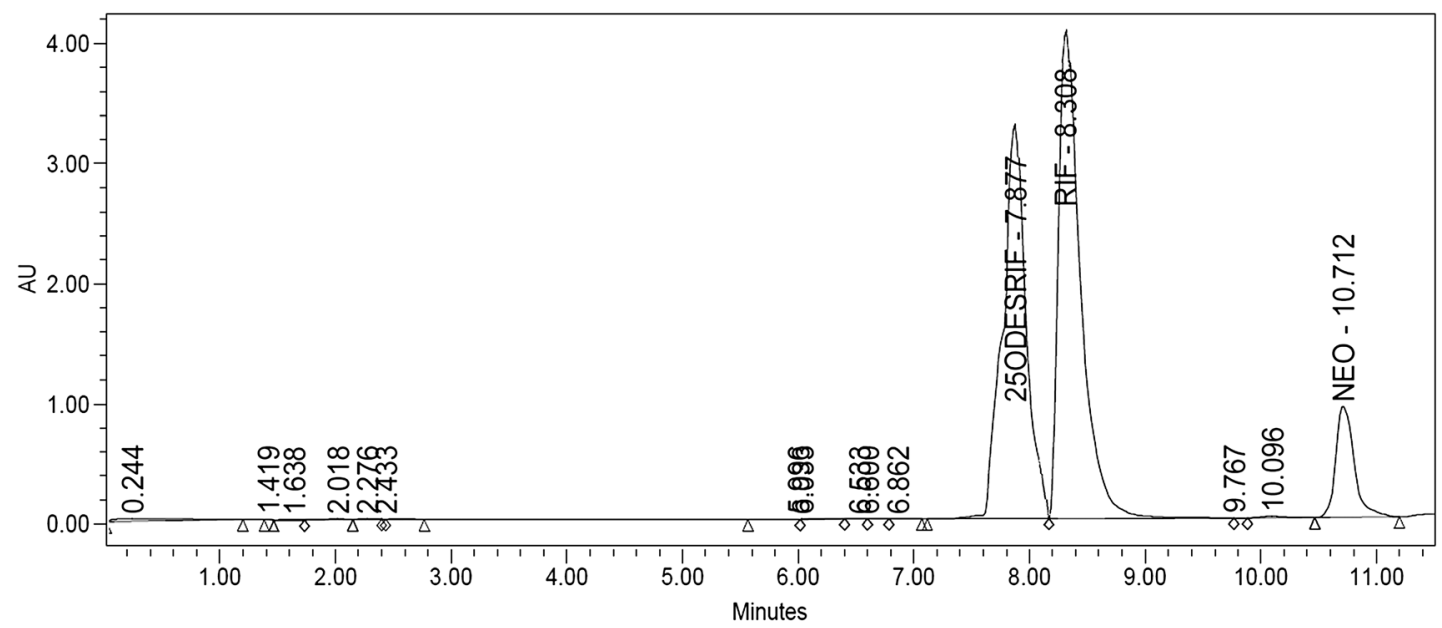

Figure 1. HPLC chromatographic separation of RIF, 25ODESRIF, and NEO using the C-18 column at $4 \mathrm{mM}$ concentrations of the drug, metabolite, and internal standard

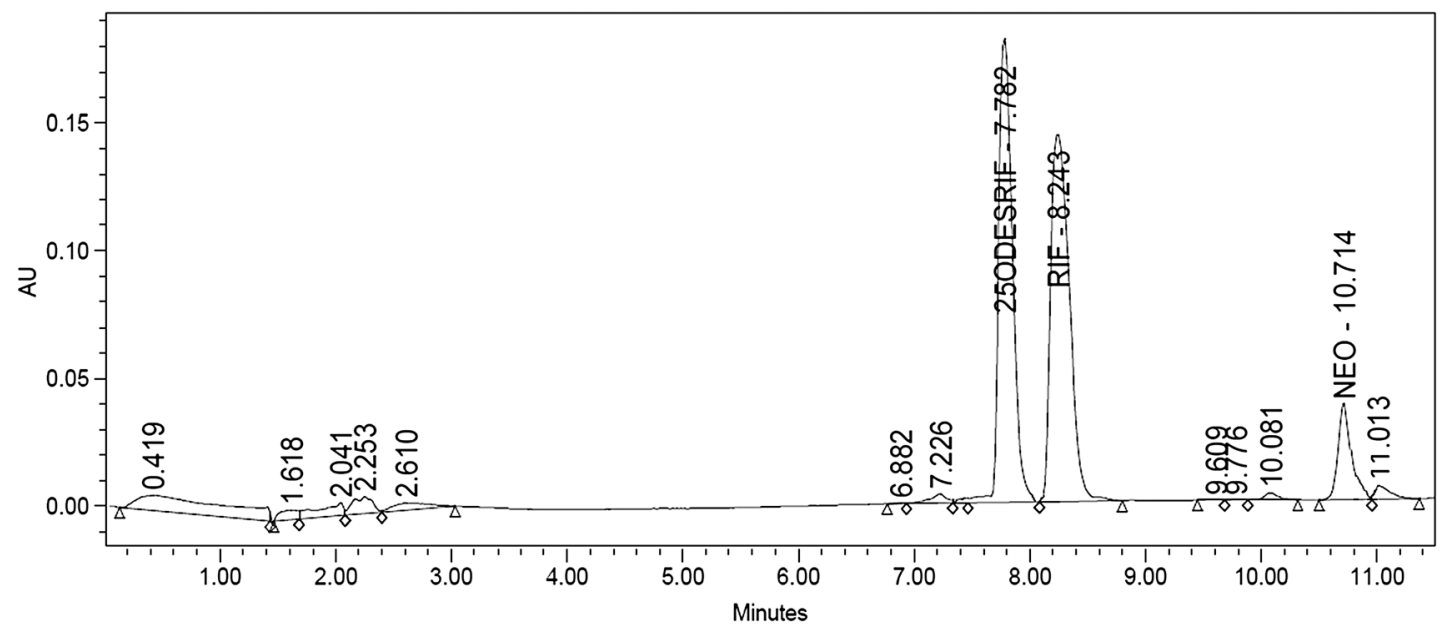

Figure 2. HPLC chromatographic separation of RIF, 25ODESRIF, and NEO using the C-18 column at $100 \mu \mathrm{M}$ concentrations of the drug and its metabolite, $20 \mu \mathrm{M}$ internal standard 
Table 3. Robustness evaluation parameters and retention time of the analytes for the HPLC method

\begin{tabular}{lcccc}
\hline Parameter & Variation & \multicolumn{3}{c}{ Retention time (min) } \\
\cline { 3 - 5 } & & RIF & 25ODESRIF & NEO \\
\hline Flow rate & $0.6 \mathrm{~mL} / \mathrm{min}$ & 8.21 & 9.03 & 11.31 \\
& $0.7 \mathrm{~mL} / \mathrm{min}$ & 7.91 & 8.53 & 10.98 \\
Temperature & $0.8 \mathrm{~mL} / \mathrm{min}$ & 7.78 & 8.25 & 10.71 \\
& $27^{\circ} \mathrm{C}$ & 7.73 & 8.27 & 10.72 \\
& $30^{\circ} \mathrm{C}$ & 7.74 & 8.25 & 10.75 \\
Wavelength & $34^{\circ} \mathrm{C}$ & 7.75 & 8.24 & 10.79 \\
& $250 \mathrm{~nm}$ & 7.75 & 8.28 & 10.68 \\
& $254 \mathrm{~nm}$ & 7.78 & 8.25 & 10.70 \\
& $257 \mathrm{~nm}$ & 7.79 & 8.26 & 10.69 \\
\hline
\end{tabular}

regression analysis was done to obtain sigmoidal plots of enzyme kinetic data for $\mathrm{IC}_{50}$, using GraphPad Software.

\section{Results and Discussion}

Development and Optimization of the HPLC Method. The separation of the three analytes was not satisfactory when using an isocratic method, especially due to interference from cofactors and secondary metabolites in the HLM assays; hence, gradient elution was selected [26]. Method optimization was done by different logical modifications such as change in column length (100 mm, $150 \mathrm{~mm}$, and $250 \mathrm{~mm})$, inner diameter $(2.6 \mathrm{~mm}$ and $4.6 \mathrm{~mm})$, particle size $(3.5 \mu$ and $5 \mu$ ), and change in the elution gradient.

The separation of all three analytes was consistent and reproducible in the $\mathrm{C}-18$ Luna column and had a shorter run time (Figures 1 and 2). The HPLC retention times were consistent at $\pm 7.70 \mathrm{~min}, \pm 8.25 \mathrm{~min}$, and $\pm 10.70 \mathrm{~min}$ for RIF, 25ODESRIF, and NEO, respectively, for the C-18 column. The overall runtime per sample analysis was $11.5 \mathrm{~min}$.

At millimolar concentrations of both drugs, the peaks were more broadened and tailing, due to the retention affinity of rifampicin and its metabolite to the column. The peak resolutions were adequate in the concentration range relevant for drug metabolism interaction studies $(0-150 \mu \mathrm{M})$.

The C-18 Luna column provided good measurable separation and consistent results for lower concentrations of both RIF and 25ODESRIF.

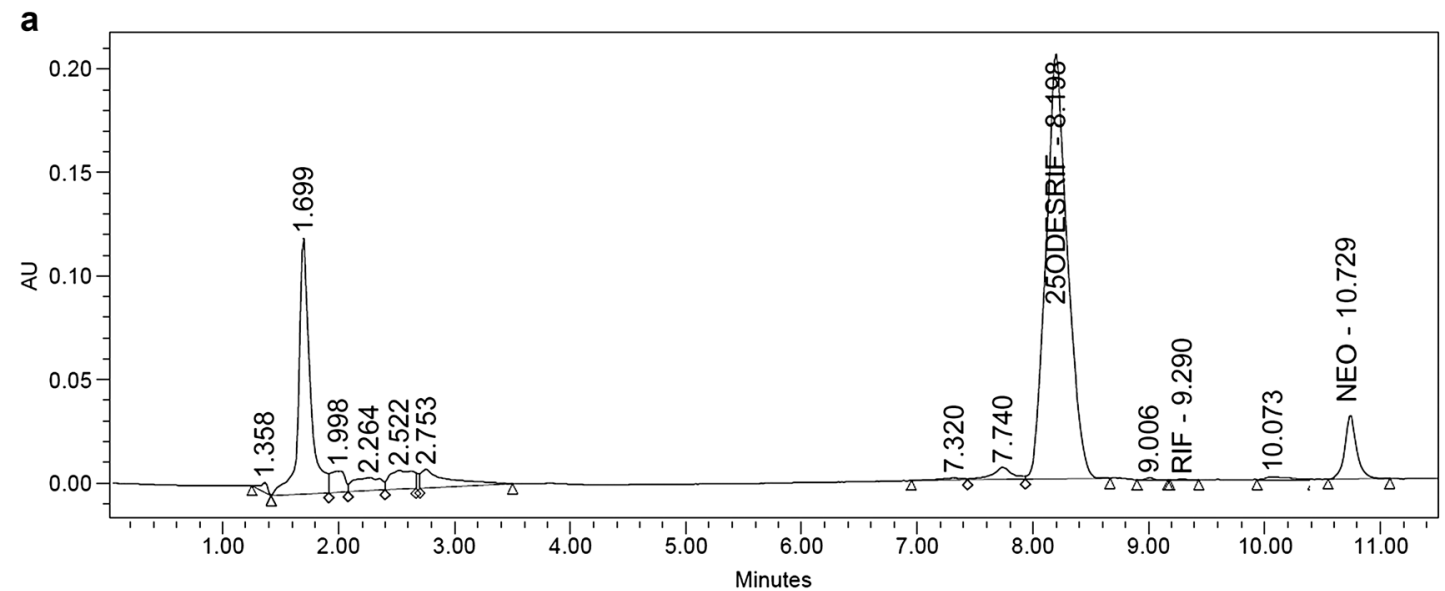

b

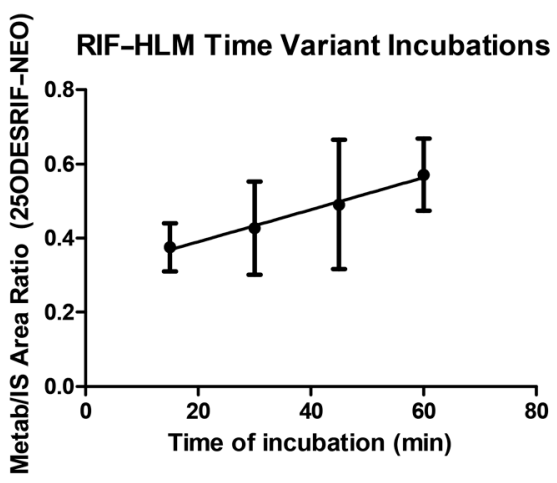

Figure 3. a. HPLC chromatographic separation of RIF, 25ODESRIF, and NEO using the C-18 Luna column, for the in vitro HLM-RIF incubation sample (75 $\mu$ M RIF). b. Linearity graph for time variant incubations with $R^{2}=0.9901$
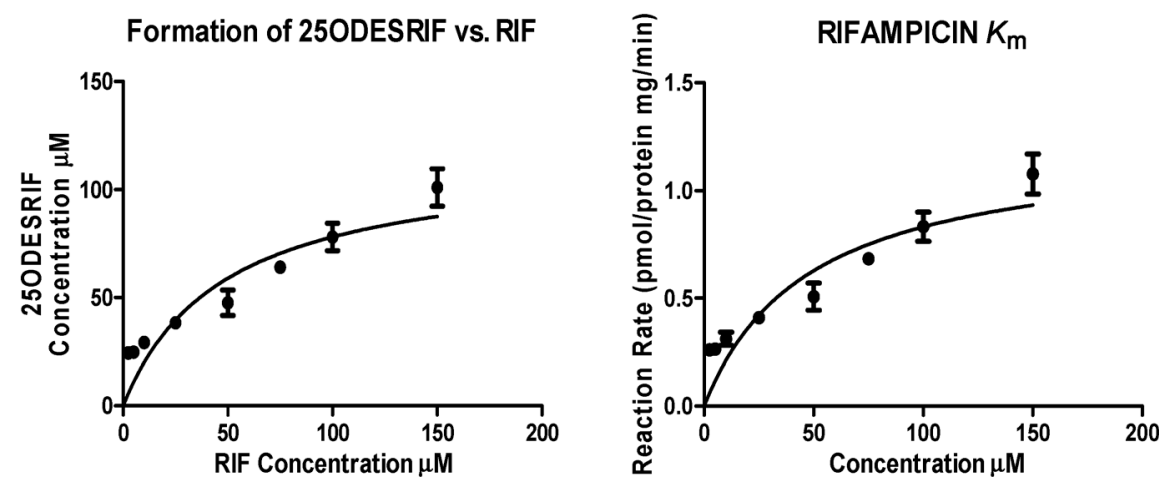

Figure 4. Kinetic analyses of RIF by human liver microsomes and formation of 25ODESRIF versus RIF 
Table 4. Kinetics of rifampicin metabolism

\begin{tabular}{lccc}
\hline HLMs & $K_{\mathrm{m}}$ & $V_{\max }$ & $\begin{array}{c}\mathrm{CL}_{\mathrm{int}} \\
\left(V_{\max } / K_{\mathrm{m}}\right)\end{array}$ \\
\hline $\begin{array}{l}\text { H0610, H0620, H0630, H0640 } \\
\text { (Pooled HLM - Mixed, Xenotech) }\end{array}$ & 48.23 & 1.233 & 0.026 \\
& \\
$\quad \mathrm{~V}_{\max }, \mathrm{pmol} / \mathrm{min} / \mathrm{mg}$ protein or $\mathrm{pmol} / \mathrm{min} / \mathrm{pmol} \mathrm{P} 450 ; K_{m}, \mu \mathrm{M} ;$ \\
$\mathrm{CL}_{\mathrm{int}}, \mu \mathrm{L} / \mathrm{min} / \mathrm{mg}$ protein or $\mu \mathrm{L} / \mathrm{min} / \mathrm{pmol} \mathrm{P} 450$.
\end{tabular}

\section{Method Validation}

Linearity, $L O D$, and $L O Q$. A linear response was obtained in the concentration range of $0-200 \mu \mathrm{M}$ for both RIF and 25ODESRIF $\left(R^{2}=0.995\right)$. LLOD and LLOQ were calculated at $5.86 \mu \mathrm{M}$ and $17.75 \mu \mathrm{M}$ for RIF and $7.78 \mu \mathrm{M}$ and $23.57 \mu \mathrm{M}$ for 25ODESRIF, respectively. The results of the system suitability tests assure the adequacy of the proposed HPLC method for a

A. officinalis Extracts vs. RIF - Two-Point Screening

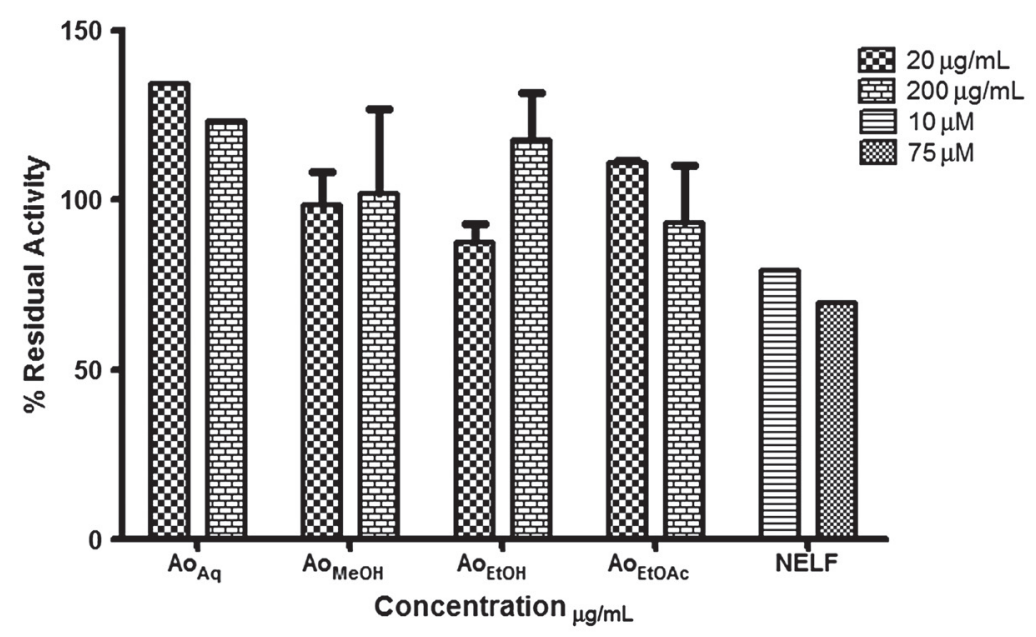

b

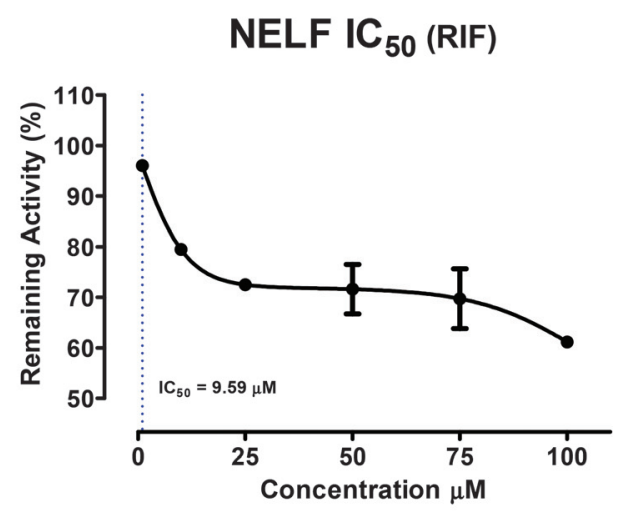

C
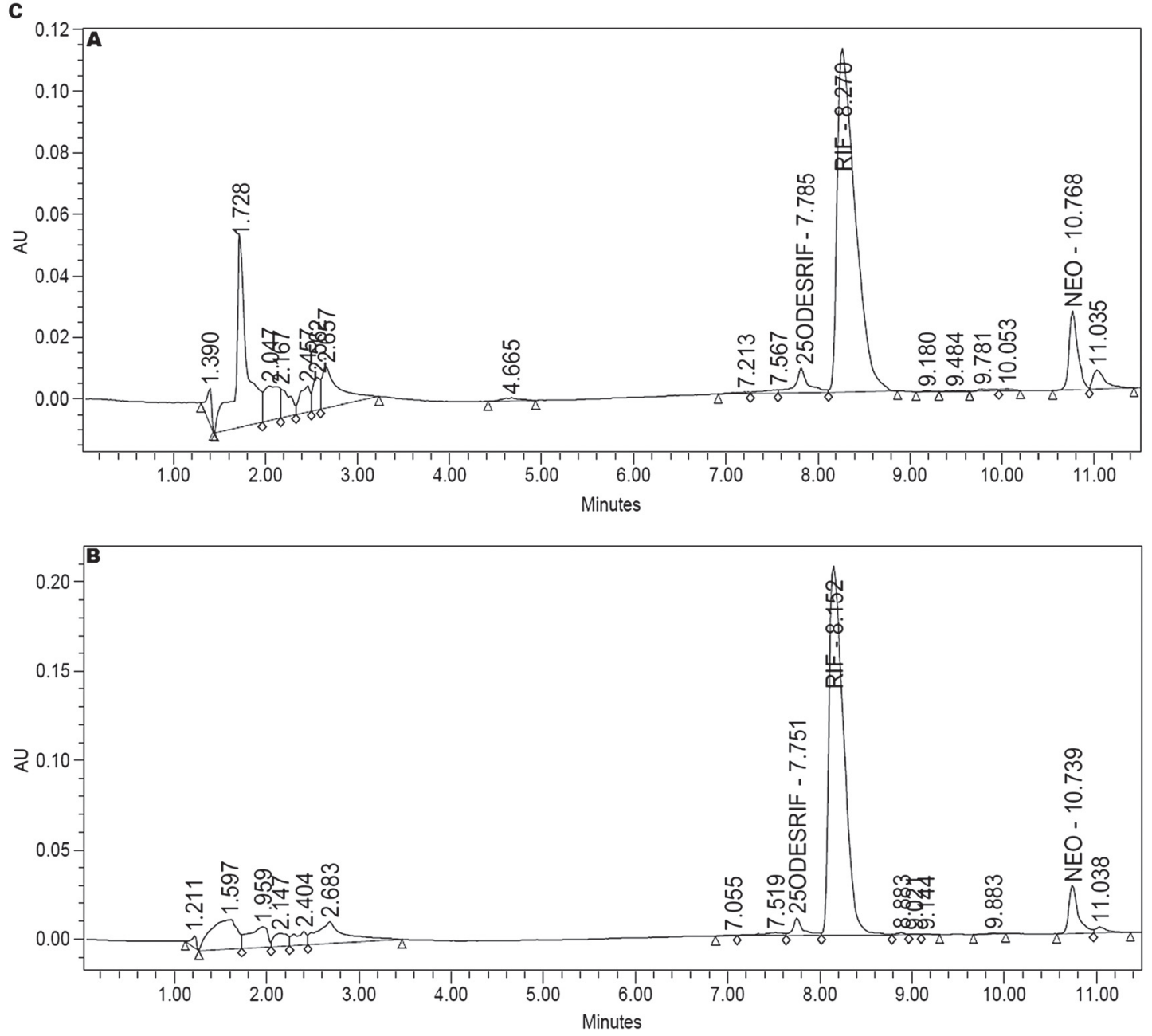

Figure 5. a. Two-point screening of the aqueous $\left(\mathrm{Ao}_{\mathrm{Aq}}\right)$, methanolic $\left(\mathrm{Ao}_{\mathrm{MeOH}}\right)$, ethanolic $\left(\mathrm{Ao}_{\mathrm{EtOH}}\right)$, and ethyl acetate $\left(\mathrm{Ao} \mathrm{EtOAc}_{\mathrm{C}}\right)$ extracts of $A$. officinalis against RIF metabolism pathway, with nelfinavir (NELF) as the positive control. b. Statistical plot (IC $\left.{ }_{50}\right)$ of the positive control NELF $(5.44 \mu \mathrm{g} / \mathrm{mL}$, $9.59 \mu \mathrm{M})$ against percentage remaining activity of rifampicin metabolism. c. HPLC chromatographic separation of RIF, 25ODESRIF, and NEO using the C-18 Luna column, for the in vitro HLM-RIF incubation samples (48 $\mu$ M RIF): A, test control (negative) incubate with no herb extract; B, assay incubate with $200 \mu \mathrm{g} / \mathrm{mL}$ aqueous extract of $A$. officinalis 
routine analysis of RIF and 25ODESRIF alone or in combination. The regression statistics are as outlined in Table 2.

Statistically Designed Robustness Experiments. Robust analytical methods using HPLC are required in quality control laboratories for routine use, as well as in experiments involving HDI/ DDI studies. After finalizing the mobile phase composition and column, statistically designed experiments were performed to screen robustness of the analytical method and to select the appropriate system suitability parameters (Table 3 ).

Specificity. The applicability of the validated HPLC method for pharmacokinetic studies was tested using in vitro human liver microsomal incubation assay. For all four time periods $(15,30$, 45, and $60 \mathrm{~min}$, in duplicates), the metabolite 25ODESRIF was detected using this method at consistent retention times along with RIF and NEO, and the peak area of NEO was relatively constant (Figure 3a).

Linearity was established for the 15-60 min incubation range based on the ratio of the metabolite to the internal standard, with $R^{2}=0.99$ (Figure 3b).

Kinetic Analyses of Rifampicin and Its Metabolite. The kinetics for the formation of 25ODESRIF from RIF was determined in several HLM incubations for concentrations in the range of $0-150 \mu \mathrm{M}$. Representative Michaelis-Menten kinetic plots from all assays are depicted in Figure 4, and the kinetic parameters are summarized in Table 4.

Two-Point Screening of Herbal Extracts with Rifampicin. The potential of the extracts of $A$. officinalis to inhibit the metabolism pathway of RIF was investigated. The solvent extracts were screened at two concentrations $(20 \mu \mathrm{g} / \mathrm{mL}$ and $200 \mu \mathrm{g} / \mathrm{mL}$ ), and the observed remaining activity was expressed as percentage of the negative control (no inhibitor). For both enzymes, less than $1 \%$ solvent was used for the total incubation, as per the assay standard guidelines; methanol inhibited rifampicin metabolism by $20 \%$ at $2 \mu \mathrm{L}$ per $200 \mu \mathrm{L}$ incubation concentration, while ethanol and ethyl acetate had no effect on the enzyme activity.

None of the extracts of $A$. officinalis showed inhibition of RIF metabolism at high and low concentrations (Figure 5a) compared to NELF which inhibited the activity by about $30 \%$ at $75 \mu \mathrm{M}$. NELF was further screened in the concentration range of $1-100 \mu \mathrm{M}$, and it was observed that, at higher concentrations, it inhibited rifampicin metabolism in HLM and had an $\mathrm{IC}_{50}$ value of $9.59 \mu \mathrm{M}(5.44 \mu \mathrm{g} / \mathrm{mL})$ (Figure $\left.5 \mathrm{~b}\right)$.

\section{Conclusions}

A specific, precise, and robust HPLC method was developed which could separate as well as accurately quantify RIF and its major metabolite 25ODESRIF. The assay yielded wellresolved peaks for RIF, 25ODESRIF, and NEO, with good accuracy, precision, and recovery, within a short run time. The suitability of the method for pharmacokinetic drug metabolism studies was validated using HLM incubations, and the kinetics of RIF were analyzed. The $K_{\mathrm{m}}$ value expressed for the formation of 25ODESRIF in HLM was calculated to be $48.23 \mu \mathrm{M}$. Previously reported values of rifampicin $K_{\mathrm{m}}$ in transporters SLCO1B1 (OATP1B1, OATP-C, OATP2, LST-1) in HeLaOATP1B1, OATP1B1-expressing oocytes, and SLCO1B3 (OATP1B3, OATP8) in OATP1B3-expressing oocytes were $1.5 \mu \mathrm{M}, 13 \mu \mathrm{M}$, and $2.3 \mu \mathrm{M}[27,28]$, respectively.

In a study on Staphylococcus aureus, based on the accumulation of ${ }^{14} \mathrm{C}$-rifampicin, the $K_{\mathrm{m}}$ value expressed was $0.06 \mu \mathrm{M}$ [29].

The in vitro data showed that 25ODESRIF is the primary metabolite, which concurs with previous studies [30, 31]. Possible interactions of RIF with herbal medicines have been reported previously [32-34]. However, not much research has been done on the effect of herbal medicine on the metabolism pathway of RIF to 25ODESRIF, which is critical because inhibition of this metabolism pathway may result in toxicity, including mortality $[35,36]$. This HPLC method was specifically used for analyzing the variations in the metabolic profile of RIF, with or without various solvent extracts of $A$. officinalis. The gradient elution provided clear separation of the secondary plant metabolites from the major metabolite of RIF and the internal standard with precision and consistency (Figure 5c), and the amount of 25ODESRIF formed for each assay was quantified relative to the negative control. A. officinalis did not cause any inhibition of this pathway.

In conclusion, this HPLC-PDA analytical method is suitable for in vitro metabolism studies of RIF, including herb or drug interaction studies.

\section{Conflicts of Interests}

The authors declared no conflicts of interest.

Acknowledgments. The authors are grateful to the South African National Research Foundation (NRF IKS Grant No. 82641) for financial support. The authors wish to thank the Bioanalytics group at Synexa Life Sciences, Cape Town for their support in this research study.

\section{References}

1. Grosset, J. Bull. Int. Union. Tuberc. 1978, 53, 5-12.

2. Jamis-Dow, C. A.; Katki, A. G.; Collins, J. M.; Klecker, R. W. Xenobiotica 1997, 27, 1015-1024.

3. Acocella, G. Clin. Pharmacokinet. 1978, 3, 108-127.

4. Hellum, B. H.; Hu, Z.; Nilsen, O. G. Basic Clin. Pharmacol. Toxicol. 2007, 100, 23-30.

5. Gurley, B. J.; Hubbard, M. A.; Williams, D. K.; Thaden, J.; Tong, Y.; Gentry, W. B.; Breen, P.; Carrier, D. J.; Cheboyina, S. J. Clin. Pharmacol. 2006, 46, 201-213.

6. Kliewer, S. A.; Willson, T. M. J. Lipid. Res. 2002, 43, 359-364.

7. Staudinger, J. L.; Chenshu, X.; Cui, Y. J.; Klaasen, C. D. Expert Opin. Drug Metab. Toxicol. 2010, 6, 261-271.

8. Smith, P. J.; van Dyk, J.; Fredericks, A. Int. J. Tuberc. Lung. Dis. 1999, 3, 325-328.

9. Ishi, M.; Ogata, H. J. Chromatogr. 1988, 426, 412-416.

10. Ratti, B.; Parenti, R. R.; Toselli, A.; Zerilli, L. F. J. Chromatogr. 1981, $225,526-531$

11. Lecaillon, J. B.; Febvre, N.; Metayer, J. P.; Souppart, C. J. Chromatogr. 1978, 145, 319-324.

12. Oldfield, S.; Berg, J. D.; Stiles, H. J.; Buckley, B. M. J. Chromatogr. 1986, 377, 423-429.

13. Panchagnula, R.; Sood, A.; Sharda, N.; Kaur, K.; Kaul, C. L. J. Pharm. Biomed. Anal. 1999, 18, 1013-1020.

14. Weber, A.; Opheim, K. E.; Smith, A. L.; Wong, K. Rev. Infect. Dis. 1983 , $5,433-9$.

15. Dimeski, G. Clin. Biochem. Rev. 2008, 29, 43-48.

16. Erikson, D. A.; Mather, G.; Trager, W. F.; Levy, R. H.; Keirns, J. J. Drug Metab. Dispos. 1999, 27, 1488-1495.

17. Ramachandran, G.; Hemanthkumar, A. K.; Rajeskaran, S.; Padmapriyadarsini, C.; Narendran, G.; Sukumar, B.; Sathishnarayan, S.; Raja, K.; Kumaraswami, V.; Swaminathan, S. J. Acquired Immune Defic. Syndr. 2004, 42, 36-41.

18. Yamashita, F.; Sasa, Y.; Yoshida, S.; Hisaka, A.; Asai, Y.; Kitano, H.; Hashida, M.; Suzuki, H. PLoS ONE 2013, 8, e70330.

19. Cravotto, G.; Boffa, L.; Genzini, L.; Garella, D. J. Clin. Pharm. Ther. 2010, $35,11-48$.

20. Sutovska, M.; Nosalova, G.; Franova, S.; Kardosova, A. Batsch Bratisl. Lek. Listy 2007, 108, 93-99.

21. Basch, E.; Ulbricht, C.; Hammerness, P.; Vora, M. J. Herb Pharmacother. 2003, 3, 71-81.

22. Mehndiratta, M. M.; Pandey, S.; Kuntzer, T. Cochrane Db. System. Rev 2014, 10, CD006986.

23. Cohen, K.; van Cutsem, G.; Boulle, A.; McIlleron, H.; Goemaere, E.; Smith, P. J.; Maartens, G. J. Antimicro Chemother. 2008, 61, 389-393.

24. ICH guideline, Q2 R1 validation of analytical procedures: text and methodology, in Proceedings of the International Conference on Harmonization, Food and Drug Administration; Rockville, MD, USA, 2005.

25. Polsky-Fisher, S. L.; Cao, H.; Lu, P.; Gibson, C. R. Drug Metab. Dispos. 2006, 34, 1361-1366.

26. Varghese, A.; Pandita, N.; Gaud, R. S. Indian J. Pharm. Sci. 2014, 76, $138-147$.

27. Tirona, R. G.; Leake, B. F.; Wolkoff, A. W.; Kim, R. B. J. Pharmacol. Exp. Ther. 2003, 304, 223-228.

28. Vavricka, S. R.; Van Montfoort, J.; Ha, H. R.; Meier, P. J.; Fattinger, K. Hepatology 2002, 36, 164-172. 
29. Williams, K. J.; Piddock, L. J. J. Antimicrob. Chemother. 1998, 42, 597-603.

30. Seng, K.; Hee, K.; Soon, G.; Chew, N.; Khoo, S. H.; Soon-U Lee, L. J. Antimicrob. Chemother. 2015, 70, 3298-3306.

31. Panchagnula, R.; Sood, A.; Sharda, N.; Kaur, K.; Kaul, C. L. J. Pharma. Biomed. Anal. 1999, 18, 1013-1020.

32. Gurley, B.; Hubbard, M. A.; Williams, D. K.; Thaden, J.; Tong, Y.; Gentry, W. B.; Breen, P.; Carrier, D. J.; Cheboyina, S. J. Clin. Pharmacol. 2006, 46, 201-213.
33. Gurley, B. J. Swain, A.; Williams, D. K.; Barone, G.; Battu, S. K. Mol. Nutr. Food Res. 2008, 52, 772-779.

34. Zutshi, R. K.; Singh, R.; Zutshi, D.; Johri, R. K.; Atal, C. K. J. Ass. Phys. India 1985, 33, 223-224.

35. Sridhar, A.; Sandeep, Y.; Krishnakishore, C.; Sriramnaveen, P.; Manjusha, Y.; Sivakumar, V. Indian J. Nephrol. 2012, 22, 385-387.

36. Cheng, J.; Fock, K. M.; Chua, K. L. Singapore Med. J. 1988, 29, 306-308. 